\title{
Relationships between mental workload, job burnout, and organizational commitment
}

\author{
Altanchimeg Zanabazar $^{1 *}$, and Sarantuya Jigjiddorj ${ }^{1}$ \\ ${ }^{1}$ Management Department, Business School, National University of Mongolia, Ulaanbaatar, Mongolia
}

\begin{abstract}
The business environment has becoming exceptionally unsteady and competitive recently. Information technology advancements and ever changing customer preferences has played a substantial role in an increase of the significance of highly productive, committed and loyal employees. These changes bring both advantages and challenges need to be addressed. The more challenges accelerate, the more issues come up to solve in timely manner. For any organizations, not only taking care of the customers but also employees of the organization should be treated equally taking a better care about their psychological and physical health as well as creating a healthy work environment. The objective of the current research is to study correlations of workload, job burnout and organizational commitment in the case of nurses working in the Health Center of Selenge aimag, Mongolia. According to the results, an increase of mental workload nurses by one unit results in job burnout increases by 0.578 (beta) unit and leads to the decrease of the organizational commitment by 0.437 (beta) unit. Moreover, one-unit increase of job burnout leads to decrease of the organizational commitment by 0.301 (beta) unit.
\end{abstract}

Keywords: Mental workload, Job burnout, Organizational commitment, nurses

\section{Introduction}

Employee loyalty ensures the organization competitive advantages [1]. Recently technology based businesses like banks and medical institutions are getting more focused on the upgrading employee loyalty, rather than years in service for the organization, bearing in mind their further contribution [2]. Therefore, for maintaining highly productive, loyal and highly committed employees the organizations are more than ever required to address employee physical and psychological health, balanced workload and healthy work environment.

An excessive mental workload, work stress and exhaustion bring negative impacts on employee loyalty as well as organizational outcomes. As a poor performance and productivity due to the job related issues often contributes to the severe damage in employee wellbeing, the scholars and business practitioners pay more attention on the mental workload [3-4].

Specially, evaluation of efficiency and mental workload is essential in a man-machine interacted work environment [5]. The significance of human factor is vital for maintaining high performance in sustainable manner [6]. To reduce unforeseen risks associated with the human activities, it is crucial to evaluate the mental workload of employees in a certain interval of time. The time pressure, multi-tasks, and hastiness not only result in high mental workload but also cause depression and job burnout which negatively impact employee's life.

\footnotetext{
${ }^{*}$ Corresponding author: altanchimegz@num.edu.mn
} 
Researchers provided different studies that identified the relationship between numerous conditions such as intense workload, the job burnout and the employee loyalty to the organization [7-8], mental workload and organizational loyalty [9], mental workload and poor performance [10], decrease of employee loyalty to the organization [11-14], decrease of job satisfaction [12] and demonstrated how these conditions might have impacted on employee wellbeing and organizational outcomes.

\section{Literature review}

\subsection{Workload}

Workload issues have been studied by various researchers, and they approached differently explaining the source of workload, mechanism and measurement. Gopher and Donchin (1986) described the work load as the interaction between mental needs of employee to perform his assigned tasks. Work quality related workload is the physical and mental challenges the employee experience while performing his work tasks. Workload is identified as the quantitative and qualitative variables [15], or mental and physical variables [16].

Mental Workload: It is important to distinguish between mental and physical workloads [16] as the causes and effects can be different in terms of theory and practice. The concept of mental workload is originated from cognitive load theory that concerns with the relations between human mind and its limitations [17]. By this theory, if a human is over or low loaded, learning new things and performing tasks are influenced negatively [18]. Taking in account this perspective, Hart described the mental workload as the adaptation and interaction between work requirements and employee's perception, talents, abilities and emotions [19]. For instance, two people performing the same tasks may end up with different outcomes. To reveal the reasons serving behind differences the mental workload may be considered and analyzed carefully [20]. Moreover, the amount of information obtained during work tasks is related to mental workload as the ability to memorize the information can affect in balancing between task demand and cognitive resources [21]. Work demand with time pressure, complex in nature increases the workload perception [22].

Vidulich and Tsang considered that mental workload is consisted of exogenous task demands and endogenous supplies of resources. Clearly, task priority, task difficulty, situational contingencies are classified as exogenous task demand while updating, perceiving memory, decision-making, planning and processing are considered as endogenous ones [20]. Mental workload is related with the characteristics of the tasks, employee's skills and abilities and environmental features of the workplace and the organization [22].

Cognitive demands for performing tasks prompt mental workload perception of employees. In this sense, mental workload is considered with the complexity of the tasks that are required to perform for daily activities [22]. Vidulich and Tsang described workload as an interaction between employee's capacity and task requirements [20]. Deviations between structure of the required tasks and human capacities affect the occurrence of the workload. It means imbalance between task demands and employee capacity, mental comes to exist.

Mental workload get attention for being a significant occupational risk factor in the workplace that leads to loss of performance, productivity, welfare and well-being [3, 4, 23]. Performance failure may increase the perception of the workload [24] and consequently, overload and fatigue speed up making mistakes and failures in the job [25].

On the other hand, when mental workload increases, control variability and errors increase and an individual performance tend to decrease. The workload related with the volume and quantity is considered in relation to the volume of the employee job tasks [26]. The workload is one of the risks in the job that may threaten employee commitment, loyalty, 
productivity, satisfaction and wellbeing [3-4].

\subsection{Job Burnout}

Job burnout is a concept that is discussed in the organizational behavior literature by Freudenberger and Maslach. Burnout described by these researchers as an overwhelming exhaustion, feelings of frustration, anger, cynicism and a sense of ineffectiveness and failure [8]. Job burnout is a negative phenomenon that is originated from the chronic job stress and causes harms regardless the nature of the occupation [27]. Burnout is an emotional and mental exhaustion that make people stranded [28].

Work overload, conflict with other people in contact often reveal the sign of burnout and it is often visibly demonstrated by loss of trust and negative attitudes towards others. When time passes feeling unhappiness, dissatisfaction about the job accomplishment lead to inability coping with their job and the suffered one evaluates himself, gets aware of the burnout. The main dimensions of job burnout considered as emotional exhaustion, depersonalization and personal accomplishment [29].

Demerouti and colleagues (2001) considered that burnout may be found in any occupational context and seen both within and outside the human services [30]. While in the beginning the theoretical concept development of burnout, it principally discussed work associated factors, however recent researchers consider that environmental and individual factors also have an effect on burn out syndrome [29-32].

Burnout occurs as a result of complicated interaction between individual characteristics and factors in the work environment [10]. According to some studies causes of burnout with a focus on the work environment indicating role stressors, organizational structures, and job characteristics. Particularly, what is stressful for one may not be stressful for another [29].

Mainly, burnout develops after continues, repeated and unsuccessful confrontation of undesirable working conditions [24]. As Karabay, Tezergil and Köse (2014) considered the reason for the burnout among people work related stress factors [33]. The factors cause the burnout situation at work and create negative circumstances. Moreover, these factors influence the performance of employees and reduce the productivity. According to Maslach (2003) burnout is a response to chronic work related stress that attempts to adapt and protect oneself from it [34].

Emotional exhaustion: The current component is considered as the key symptom of burnout, and it is strongly related with other components. Emotional exhaustion refers to the feelings of being emotionally over extended and exhausted by one's work. It is regarded as a lack of energy and feeling that one's emotional resources are used up. As Maslach (1982) described it as it as a response for the overwhelming emotional demands of other people. Individuals who are emotionally exhausted lack enough energy to face another day, and often report that they are filled with dread at the prospect of returning to work for another day.

Depersonalization: The next component of burnout is depersonalization. Researcher consider it as defensive coping response to deal with the effects of emotional exhaustion when alternative coping resources are not in a place. When the one suffer from burnout often developed a detached, callous or dehumanized responses to the people they should to care for. It also involves the development of negative attitudes and feelings towards persons for whom work is done. It may be expressed as unprofessional comments towards coworkers, blaming others for their problems. Generally, it is a distant attitude towards work.

Diminished personal accomplishment: It is the tendency to negatively evaluate the worth of one's work, feeling insufficient to perform his job, and a generalized poor professional self-esteem. Individuals with burnout syndrome show some symptoms like frustration, anger, fear and anxiety as well as some physical discomfort including insomnia, headache, paroxysm and even digestive track discomfort. Diminished personal accomplishment is a tendency where professional value their own capacity to carry out tasks and to interact with 
coworkers and feeling dissatisfied with achievements. Often job burnout results from an unpleasant work environment, frequent incident of unfavorable conditions and a long time progressing stress [10] that negatively affects on employee productivity, job satisfaction and encourage employee turnover intention.

\subsection{Organizational commitment}

Organizational commitment can be perceived as the trust built up among the employees. Committed employees possess a sense of obligation to provide a loyal service to the organization in the future as the one feel confident within the organizational climate [35].

Loyal and committed employees are a valuable asset for the organization as they are capable generating significant amount of profit. The employee emotional attachment and connection to the organizational decides if the employee will be committed or not. Employee loyalty and job satisfaction are crucial in the organization's achievements and only committed and satisfied with their job employees are key for maintaining an effective cooperation with the business's main stakeholders. As an employee communication and job satisfaction are contributing to the increase of the commitment, giving a special focus on these issues enable organizations increasing their employee commitment [36].

Meyer and Allen (1991) identified 'three component model of commitment', namely affective commitment, continuance commitment and normative commitment.

Affective Commitment: Affective commitment refers to a strong psychological engagement that make the ones to be loyal to the organizational goals, values and coworkers. If the he or she considers that the organizational goals and values are consistent with personal values, aspirations they tend to become more committed and loyal to the organizations. Numerous factors such as work tasks challenge the employees, clarity of job responsibilities, clarity of goals, management attitude towards to the employees, team unity, equality, respects for individuality, feedback from managers, participation and dependence on others also impact to the employee commitment.

Continuance Commitment: It relates to the degree employee's sense if they need to stay at their organization based on their reflection of costs and benefits of staying or moving to another organization. When an employee feels the need continuing with their present employer because of their wage and fringe benefits would not improve if they move to another organization cause this type of commitment and make them stay with the present employer. Employees with multiple years of experience of working at the same organization or seniority often contribute enjoying multiple benefits and make them stay committed to the organization, however it is not always because of enthusiasm.

Normative Commitment: Normative commitment refers to employee's feeling of obligation to the organization and the belief that continuing their work at the organization is the right thing. Regardless the benefits and job satisfaction the employees remain committed to the organization. High employee commitment can be seen by their devotion to fulfill the organization's goals, improvement of productivity and efficiency and provision of a quality service to the customers.

Employees contribution to the achievement of the organizational goals and objectives are valuable. Only maintaining a favorable work environment, work life balance as well as their wellbeing enable employees to become committed to the organization. Ensuring these factors in sustainable manner require HR managers to understand and research the state of employees' mental workload and job burnout to better recognize how their employees are committed to the organization.

Numerous studies are conducted to realize the relationships between these factors, including the relationships between job burnout and organizational commitment by Brown and his associates (2019), the relationships between psychological condition, organizational 
commitment and job burnout by Peng and researchers (2013)and correlations between organizational commitment, job burnout, psychological condition and anxiety by Zhou and researchers (2018). Moreover, Lin and researchers (2013) conducted the study on the impact of stress, job burnout, employee satisfaction to the organizational commitment. Also Abbas, Kanwal, \& Iqbal (2014) and Usman \& Raja (2013) conducted similar studies on the relationships between above said factors.

\subsection{Research design}

Upon reviewing the research designs and results of the above researches conducted earlier we proposed the following research design.

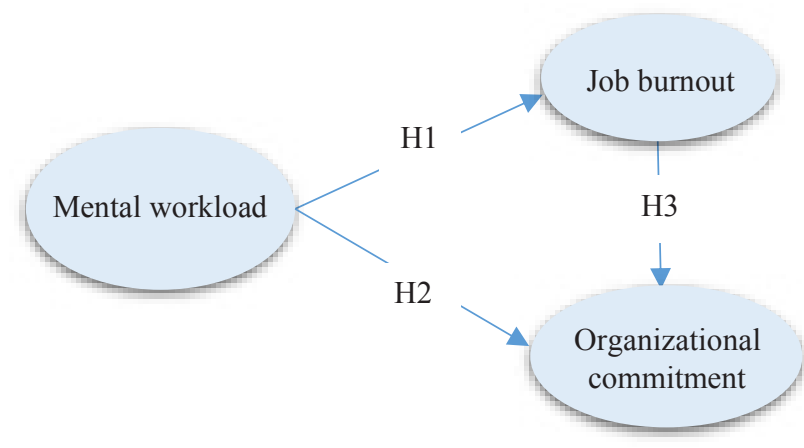

Figure 1. Research design

Source: Own processing.

\subsection{Research hypothesis}

We proposed the following hypothesis for the study:

H1: Mental workload exposure causes job burnout.

H2: Mental workload influences to the organizational commitment.

H3: Job burnout influences to the organizational commitment.

\section{Research methodology}

\subsection{Research method}

The current survey is conducted to identify if mental workload and job burnout impact on the organizational commitment in the case of nurses working in the Health Center of Selenge aimag. The survey data is processed using SPSS 23.0 and Smart PLS 3.0. The results are produced based on the results of factor analysis, reliability test, correlation and regression analysis and PLS analysis.

Sample: The population of nurses working in the above mentioned medical facility is 175 and selection of 120 nurses for the survey could present the population with $95 \%$ confidence level of probability. The data of 124 questionnaires is considered for the further analysis.

Data collection: Online survey is conducted between June 28 and July 19, 2021 and 124 nurses participated in the survey. We used various questionnaires such as CarMen-Q workload survey developed by Rubio-Valdehita \& et al (2017), MBI-HSS survey on job burnout by Maslach and Jackson (1981) and OCQ survey on organizational commitment by Meyer and Allen (1997). 
Demographic characteristics of the participants are summarized in the below.

Table 1. Demographic characteristics of the respondents

\begin{tabular}{|c|c|c|c|c|c|c|c|c|}
\hline Age & No & $\mathbf{\%}$ & Sex & Number & $\mathbf{\%}$ & Marital status & No & $\mathbf{\%}$ \\
\hline $20-24$ & 4 & 3.2 & Male & 19 & 15.3 & Married & 104 & 83.9 \\
\hline $25-29$ & 4 & 3.2 & Female & 105 & 84.7 & Single & 20 & 16.1 \\
\hline $30-34$ & 40 & 32.3 & Work experience & Too & $\mathbf{\%}$ & Other & - & - \\
\hline $35-39$ & 16 & 12.9 & up to 1 year & 8 & 6.5 & $\begin{array}{c}\text { Amount of salary } \\
\text { (MNT) }\end{array}$ & No & $\mathbf{\%}$ \\
\hline $40-44$ & 34 & 27.4 & $1-4$ years & 4 & 3.2 & Up to 600,000 & 4 & 3.2 \\
\hline $45-49$ & 15 & 12.1 & $5-9$ years & 52 & 41.9 & $600,001-750,000$ & 4 & 3.2 \\
\hline $50-54$ & 7 & 5.6 & 10-14 years & 35 & 28.2 & $750,001-900,000$ & 51 & 41.1 \\
\hline $\begin{array}{c}55 \text { and } \\
\text { above }\end{array}$ & 4 & 3.2 & $\begin{array}{c}\text { More than } 15 \\
\text { years }\end{array}$ & 25 & 20.2 & $900,001-1,100,000$ & 35 & 28.2 \\
\hline $\begin{array}{c}\text { If you have } \\
\text { children }\end{array}$ & No & $\mathbf{\%}$ & Type of work & Too & $\mathbf{\%}$ & $1,100,001-1,300,000$ & 15 & 12.1 \\
\hline Yes & 104 & 83.9 & Regular day & 108 & 87.1 & $1,300,001-1,500,000$ & 15 & 12.1 \\
\hline No & 20 & 16.1 & By shift & 16 & 12.9 & $1,500,001$ and more & - & - \\
\hline
\end{tabular}

Source: Own processing.

Only $15.3 \%$ of the participants of the survey were male and it can be concluded that the majority of the professionals are female. By marital status, majority of nurses are married (83.9\%) and only minority (16.1\%) are single ones. By age, $51.6 \%$ of the respondents were young people who are below 40 years old, $39.5 \%$ of them were at their early 50 s. Majority of the married professionals had children and only unmarried people tended to have no children.

By work experience, $6.5 \%$ of the respondents have up to one-year experience, $3.2 \%$ worked 1-4 years of experience, $41.9 \%$ have 5-9 years of work experience, $28.2 \%$ of them worked 10-14 years and $20.2 \%$ of respondents worked more than 15 years. By type of work, $87.1 \%$ engaged in regular day work and $12.9 \%$ of them worked by shifts. By wage size, $47.5 \%$ earn up to $900.000 \mathrm{MNT}, 28.2 \%$ earn between $900,001-1,100,000 \mathrm{MNT}, 12.1 \%$ earn $1,100,001-1,300,000 \mathrm{MNT}$, and $12.1 \%$ of them earn 1,300,001-1,500,000 MNT. It shows that the salary level of the medical professionals, particularly nurse's salary is very low.

It is said that $67.7 \%$ of the respondents had a sickly leave within a year due to Covid19 (33.9\%), heart and vascular disease (27.4\%) and gastroenterological, joint and muscle diseases $(3.2 \%)$. It can be concluded that nurse's job is one of the riskiest job among the medical professions.

\section{Result and Discussions}

\subsection{Reliability test}

For verification of the reliability of the questionnaire Cronbach's Alpha value has been checked as it must reach 0.7 [37] and in our case Cronbach's Alpha value for all variables fully reliable for measuring the proposed variables. Moreover, composite reliability coefficient all presented more than 0.5 [38] which means that all composites included in the questionnaire are capable to measure. Calculation of an Average Variance Extracted showed 0.5 [38] which means the reliability of the model is acceptable. As composite reliability coefficient estimation presented 0.5 as compatible [39] and the composites with coefficient less that 0.5 excluded [40]. In the analysis we used only composites with 0.5 values [41]. The results of the test are summarized in the table 2 . 
Table 2. The results of reliability test

\begin{tabular}{|c|c|c|c|c|c|}
\hline Factors & $\begin{array}{c}\text { Number of } \\
\text { questions }\end{array}$ & $\begin{array}{c}\text { Factor } \\
\text { loading }\end{array}$ & $\begin{array}{c}\text { Cronbach's } \\
\boldsymbol{\alpha}\end{array}$ & AVE & CR \\
\hline Mental workload-MW & 25 & $0.628-0.885$ & .970 & .964 & .825 \\
\hline Job burnout -JB & 15 & $0.611-0.883$ & .881 & .896 & .673 \\
\hline $\begin{array}{c}\text { Organizational } \\
\text { commitment -OC }\end{array}$ & 15 & $0.609-0.889$ & .830 & .851 & .591 \\
\hline
\end{tabular}

Source: Own processing.

\subsection{Correlation analysis}

Results of correlation analysis is shown in Table 3.

Table 3. Results of correlation analysis

\begin{tabular}{|c|c|c|c|c|}
\hline \multirow{2}{*}{ Correlations } & OC \\
\hline \multirow{2}{*}{ MW } & Pearson Correlation & MW & JB & \\
& Sig. (2-tailed) & & & \\
\hline \multirow{2}{*}{ JB } & Pearson Correlation & $.455^{* *}$ & 1 & \\
& Sig. (2-tailed) & .000 & & \\
\hline \multirow{2}{*}{ OC } & Pearson Correlation & $-.370^{* *}$ & $-.575^{* *}$ & 1 \\
& Sig. (2-tailed) & .000 & .000 & \\
\hline
\end{tabular}

** Correlation is significant at the 0.01 level (2-tailed).

* Correlation is significant at the 0.05 level (2-tailed).

Source: Own processing.

The results of the analysis show that the correlation between mental workload of nurses and organizational commitment have a weak correlation $[\mathrm{r}=-.370, \mathrm{p}<0.01]$ while job burnout and organizational commitment presented a visible correlation $[\mathrm{r}=-.575, \mathrm{p}<0.01]$.

\subsection{Structural Equation Modeling}

To ensure the reliability of data and evaluation of the model we estimate R-Squared to better predict the structural equation modeling. Through an estimate of relations between movements of a dependent variables based on an independent variables movement we found that the data and predictions unbiased or significance $(p<0.05)$. The results are shown in the following Table 4:

Table 4. Research Results of PLS-SEM

\begin{tabular}{|c|c|c|c|c|c|}
\hline Hypothesis & Path & $\begin{array}{c}\text { Standardize } \\
\text { Beta }\end{array}$ & t value & $\begin{array}{c}\text { P } \\
\text { value }\end{array}$ & Remarks \\
\hline H1 & MW $\rightarrow$ JB & $0.578^{* * *}$ & 5.641 & .000 & Supported \\
\hline H2 & $\mathrm{MW} \rightarrow \mathrm{OC}$ & $-0.437^{* * *}$ & 9.763 & .000 & Supported \\
\hline $\mathrm{H} 3$ & $\mathrm{JB} \rightarrow \mathrm{OC}$ & $-0.301^{* * *}$ & 10.896 & .000 & Supported \\
\hline
\end{tabular}

Source: Own processing.

As the results show that mental workload and job burnout $[\beta=0.578 ; \mathrm{p}<0.01]$ notably affects to the organizational commitment $[\beta=0.437 ; p<0.01]$, while job burnout has a weak impact to the organizational commitment $[\beta=0.301 ; p<0.01]$. 
Determination coefficient ( $\mathrm{R}$ squared) of 0.434 can be explained that these factors explain the relationships by $43.4 \%$ and remaining are explained by other factors that are not inclusive in the equation.

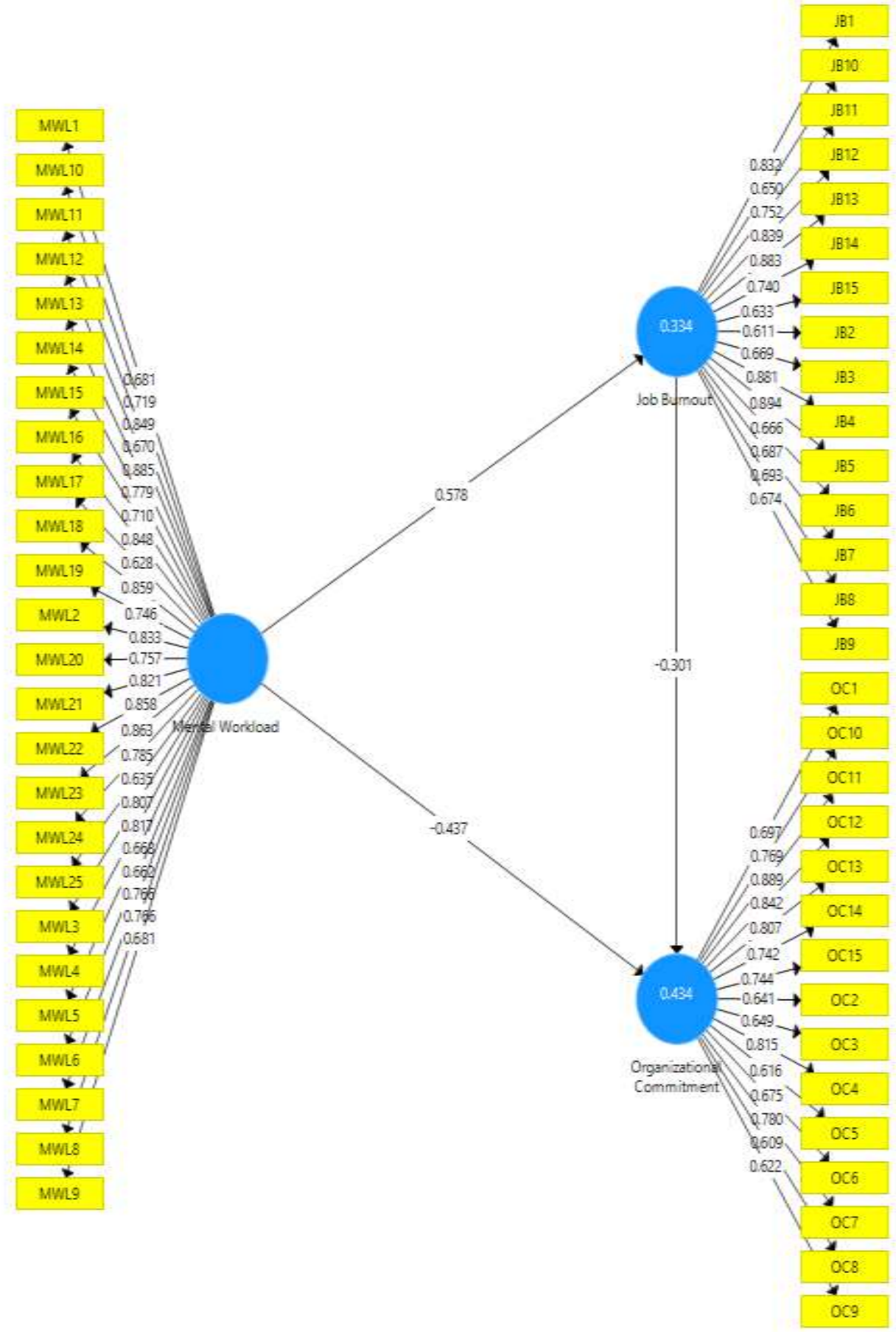

Figure 2. Path Model and PLS-SEM Estimate

Source: Own processing. 
We conclude that all proposed hypothesizes are supported as the beta coefficient of all variables are positive and statistically significant $(\mathrm{p}<0.05)$.

\section{Conclusion}

Employee commitment ensures the long term organizational sustainability maintaining the prestige, values and organizational culture that is an asset reaching the competitive advantage over competitors. Therefore, for keeping the employee efficiency, commitment, their active participation in organizational life the employers need to give a significance on mental and physical health of employees, balancing the workload and creation of healthy work environment.

The current research is examined the relationships between mental workload, job burnout and organizational commitment. Upon reviewing related theoretical framework and researches on mental workload, job burn syndrome, organizational commitment we proposed hypothesis on the relationships between the above said variables. We developed a questionnaire with Likert 5 scale measurement based on the frameworks and instruments developed earlier such as CarMen-Q developed by Rubio-Valdehita \& et al (2017), MBIHSS instrument by Maslach and Jackson (1981) and OCQ survey Meyer and Allen (1997). We survey is conducted among 124 nurses working for the Health Center of Selenge aimag.

According to the results, the case of the nurses of The Health Center of Selenge aimag show that an increase of mental workload nurses by one unit results in job burnout increases by 0.578 (Beta) unit and leads to the decrease of the organizational commitment by 0.437 (Beta) unit. Moreover, one-unit increase of job burnout leads to decrease of the organizational commitment by 0.301 (Beta) unit. Based on the results of the study we make the following conclusions:

1. Time pressure, multitask handling, urgency and heavy workload often lead to the stress and job burnout which negatively affect one's life [7].

2. We observed that the greater mental workload, the job burnout increases simultaneously $[\beta=0.578 ; p<0.00]$. In other words, the more people feel more time pressure, stress and cognitive needs they feel exhaustion and job burnout. The results of study by Keser \& Y1lmaz (2014), Rubio-Valdehita \& et al (2017) and Liu \& Lo (2018) all evidenced the above said.

3. The more the employees feel the mental workload, the organizational commitment decreases accordingly $[\beta=-0.437 ; p<0.00]$. Clearly, the more people feel more time pressure, stress and cognitive needs they feel exhaustion and job burnout on their jobs they tend to under deploy their knowledge and skills to perform the job as well lose interests to continue the work. The results of study demonstrated that mental workload negatively affect the organizational commitment is fully consistent with the results of the study conducted by Ziaei \& et al (2015), Kanchanapa \& Karnsomdee (2019), Ahuja \& et al (2002), Rodríguez-Fernández, Herrera, \& de las Heras-Rosas (2021).

4. The study results show that job burnout contributes to the decrease of the organizational commitment $[\beta=-0.301 ; p<0.00]$. Job burn syndrome causes various negative impacts towards to the job such as decrease of productivity, depersonalization, absenteeism, decreased level of job satisfaction, abuse of tobacco, alcohol and even coffee, loss of self-confidence and often contributes to the organizational performance which can be observed by decline of productivity, an increase of employee turnover, increase of training \& development expenditure and decrease of customer satisfaction level. The current finding is also consistent with the results of the studies conducted by Peng \& et al (2013), Lin, Lin, \& Cheng (2013), 
Abbas, Kanwal, \& Iqbal (2018), Zhou \& et al (2018) and Brown, Walters, \& Jones (2019).

We should note that the current study has some limitations in terms of scale and scope of the case of study as it conducted among the employee of only one local medical institution. Further, it needs to expand the coverage of the institutions of the current sector as well as the number of professionals to be involved in the study to improve its' practical benefits for the human resource management of the medical institutions operating throughout the country to enable them to better understand the job burnout syndrome that prevailing in the institutions and better address the issues preventing such negative phenomena in the job.

\section{References}

1. C. Foster, P. Whysall, L. Harris, Employee Loyalty: An Exploration of Staff Commitment Levels towards Retailing, the Retailer and the Store. International Review of Retail, Distribution \& Consumer Research, 18 (4), 423-435 (2008)

2. S. K. Aityan, T. P. Gupta, Challenges of Employee Loyalty in Corporate America. Business and Economics Journal, BEG-55 (2012)

3. A. Keser, G. Y1lmaz, Workload, Burnout, and Job Satisfaction Among Call Center Employees. Sosyal Siyaset Konferansları Dergisi, (66-67), 1-13 (2014)

4. H. L. Liu, V. Lo, An integrated model of workload, autonomy, burnout, job satisfaction, and turnover intention among Taiwanese reporters. Asian Journal of Communication, 28(2), 153-169 (2018)

5. M. Ortiz-Solis, et al., Human Error Identification and Mental Workload Index Setting During a Computer Power Source Change Task: A Case Study. Advances in Manufacturing. Production Management and Process Control, 427-438 (2019)

6. K. C. Soto, et al., Effects of Human Factors in Planning and Production Control Activities in Remanufacturing Companies. Advances in Ergonomics of Manufacturing: Managing the Enterprise of the Future, 465-474 (2016)

7. M. Ziaei, et al., Level of Workload and Its Relationship with Job Burnout among Administrative Staff. International Journal of Occupational Hygiene, 7, 53-60 (2015)

8. S. Kanchanapa, P. Karnsomdee, The influence of perceived Workload and Job burnout on Organizational commitment of employee of Thailand Post Co., Ltd. Sakon Nakhon Post Office, Thailand. International Academic Research Conference, 286-292 (2019)

9. M. Rodríguez-Fernández, J. Herrera, C. de las Heras-Rosas, Model of Organizational Commitment Applied to Health Management Systems. International Journal of Environmental Research and Public Health, 18(9), 4496 (2021)

10. C. M. Kokkinos, Job stressors, personality and burnout in primary school teachers. The British Journal of Educational Psychology, 77(1), 229-243 (2007)

11. J. Peng, et al., The Impact of Psychological Capital on Job Burnout of Chinese Nurses: The Mediator Role of Organizational Commitment. PLoS ONE, 8(12), e84193 (2013)

12. J. Lin, C. Lin, C. Cheng, A Study of the Relationship between Job Stress, Job Burnout, Job Satisfaction and Organizational Commitment among Medical Radiologists in Taiwan. Journal of Information and Optimization Sciences, 34 (2-03), 149-167 (2013)

13. Z. Abbas, A. Kanwal, J. Iqbal, Impact of Job Burnout on Organizational Commitment of Universities in Lahore, Pakistan. Minhaj Journal of Economics and Organization Science - MJEOS, 1(1), 84-99 (2018)

14. J. Zhou, et al., Serial multiple mediation of organizational commitment and job burnout in the relationship between psychological capital and anxiety in Chinese female nurses: A cross-sectional questionnaire survey. International Journal of Nursing Studies, 83, 75 $82(2018)$ 
15. L. E. Tetrick, et al., A comparison of the stress-strain process for business owners and nonowners: Differences in job demands, emotional exhaustion, satisfaction, and social support. Occupational Health Psychology, 5(4), 464-476 (2000)

16. D. J. Dwyer, D. C. Ganster, The effects of job demands and control on employee attendance and satisfaction. Organizational Behavior 12(7), 595-608 (1991)

17. C. D. Wickens, Multiple Resources and Mental Workload. Human Factors The Journal of the Human Factors and Ergonomics Society, 50(3), 449-455 (2008)

18. L. Longo, Experienced mental workload, perception of usability, their interaction and impact on task performance. PLoS ONE, 13(8), e0199661 (2018)

19. S. G. Hart, NASA-Task Load Index (NASA-TLX); 20 years later. Proceedings of the Human Factors and Ergonomics Society Annual Meeting, 50, 904-908 (2006)

20. M. A. Vidulich, P. S. Tsang, Mental workload and situation awareness. In G. Salvendy, Handbook of human factors and ergonomics (4 ${ }^{\text {th }}$ Eds), (pp. 243-273). Hoboken, NJ: Wiley (2012)

21. R. Parasuraman, T. B. Sheridan, C. D. Wickens, Situation Awareness, Mental Workload, and Trust in Automation: Viable, Empirically Supported Cognitive Engineering Constructs. Journal of Cognitive Engineering and Decision Making, 2(2), 140-160 (2008)

22. M. S. Young, et al., State of science: Mental workload in ergonomics. Ergonomics, 58(1), 1-17 (2015)

23. S. Rubio-Valdehita, et al., Development of the CarMen-Q Questionnaire for mental workload assessment. Psicothema, 29(4), 570-576 (2017)

24. E. Demerouti, et al., The job demands-resources model of burnout. Journal of Applied Psychology, 86(3), 499-512 (2001)

25. K. A. Brookhuis, D. de Waard, Monitoring drivers' mental workload in driving simulators using physiological measures. Accident Analysis \& Prevention, 42(3), 898903 (2010)

26. X. X. Che, et al., Stressors beget stressors: The effect of passive leadership on employee health through workload and work-family conflict. Work and Stress, 31(4), 338-354 (2017)

27. H. J. Freudenberger, Burn-out: the high cost of high achievement. New York: Anchor Press, (pp. 211) (1980)

28. M. Westman, D. Eden, Effects of a respite from Work on burnout: Vacation relief and fade-out. Applied Psychology, 82(4), 516-27 (1997)

29. P. S. Lau, et al., Do Demographic Characteristics Make a Difference to Burnout Among Hong Kong Secondary School Teachers? Social Indicators Research, 71(1-3), 491-516. https://doi.org/10.1007/s11205-004-8033-z (2006)

30. H. J. Kim, K. H. Shin, W. T. Umbreit, Hotel job burnout: The role of personality characteristics. International Journal of Hospitality Management, 26(2), 421-434 (2007)

31. E. Demerouti, et al., Job Crafting Interventions: Do They Work and Why? Positive Psychological Intervention Design and Protocols for Multi-Cultural Contexts, 103-125 (2019) 